\title{
Mass Spectrometric Back Reaction Screening of Quasi- Enantiomeric Products as a Mechanistic Tool
}

Patrick G. Isenegger, Andreas Pfaltz*[a]

Dedicated to Professor Ryoji Noyori in admiration of his ground-breaking achievements in asymmetric catalysis.

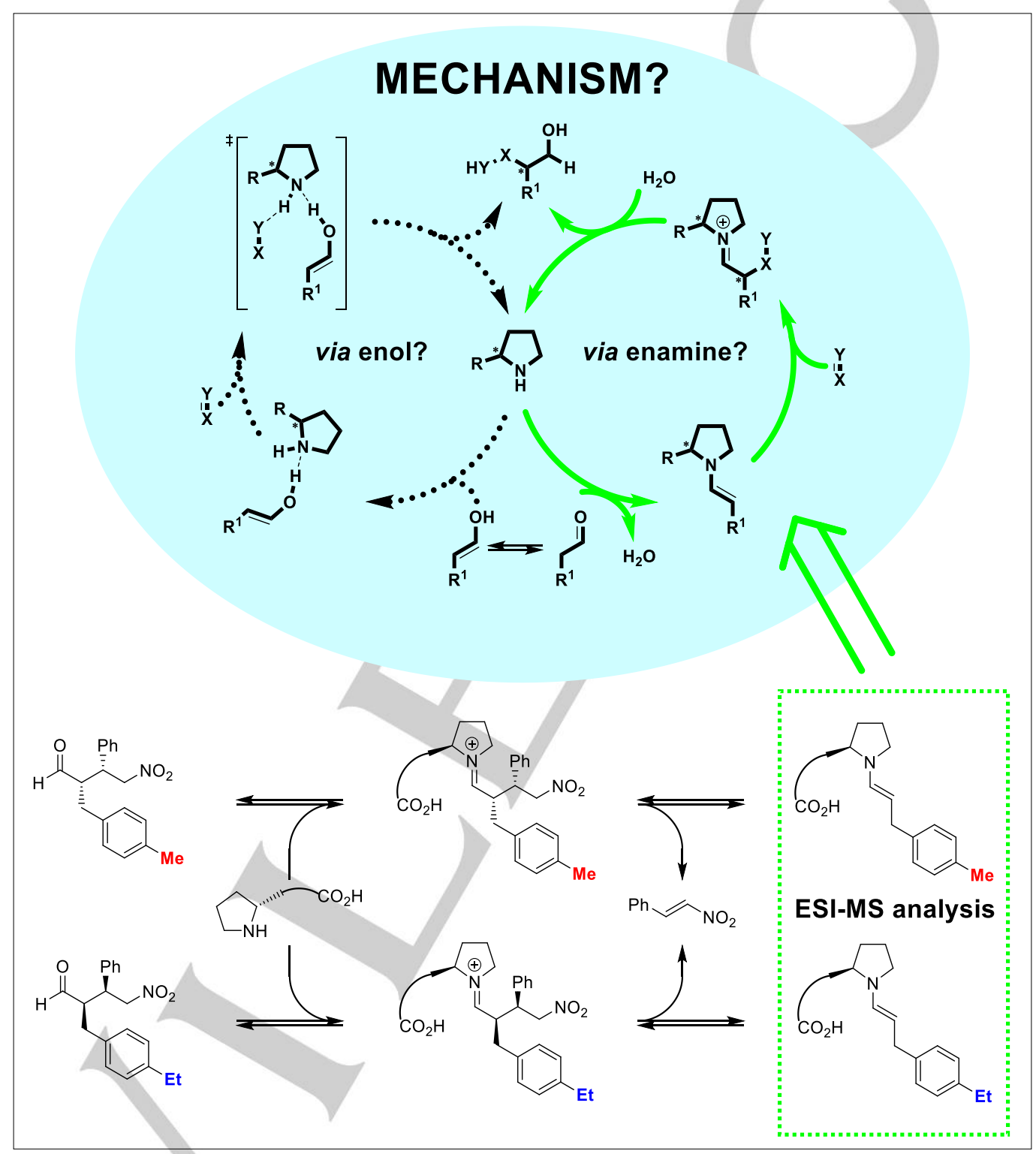

[a] P. G. Isenegger, Prof. Dr. A. Pfaltz

Department of Chemistry, University of Basel

St. Johanns-Ring 19, 4056 Basel (Switzerland)

E-mail: andreas.pfaltz@unibas.ch 
Abstract: In this account we discuss a mass spectrometric method that enables unambiguous identification of intermediates involved in the enantioselective step of a catalytic cycle. This method, which we originally developed for rapid evaluation of chiral catalysts, is based on monitoring the back reaction of mass-labeled quasi-enantiomeric products by electrospray ionization mass spectrometry (ESI-MS). In this way the intrinsic enantioselectivity of a chiral catalyst can be determined directly by quantification of catalytically relevant intermediates. By comparing the results from the forward and back reaction, direct evidence for the involvement of a catalytic intermediate in the enantioselective step can be obtained. In addition, insights about the energy profile of the catalytic cycle may be gained The potential of back reaction screening as a mechanistic tool is demonstrated for organocatalytic aldol reactions, 1,4-additions of aldehydes to nitroolefins, Diels-Alder reactions, Michael additions, and Morita-Baylis-Hillman reactions.

\section{Introduction}

Asymmetric catalysis has seen enormous growth over the last two decades. An impressive selection of enantioselective catalytic reactions has become available that covers a wide spectrum of synthetically useful transformations. ${ }^{[1]}$ However, our understanding of the mechanisms responsible for enantioselection is lagging behind. In most cases the observed enantioselectivity has been rationalized by qualitative hypothetical models. Enantioselective reactions like the rhodium-catalyzed asymmetric hydrogenation of acetamido acrylates, for which a detailed mechanism has been securely established, ${ }^{[2]}$ are scarce. Therefore, development of new chiral catalysts still depends to a large extent on trial and error rather than rational design, despite the rich arsenal of spectroscopic and computational methods available today.

The main problems that make it so difficult to determine the enantioselectivity-determining step in a catalytic process and to identify the intermediates involved, are the low concentration and short lifetime of catalytic intermediates. Moreover, in general other species are present in the reaction solution that are not involved in the catalytic cycle. Such species, which may be in equilibrium with catalytic intermediates or result from irreversible catalyst deactivation, complicate spectroscopic analyses. So even if a postulated intermediate has been characterized, e.g. by NMR or mass spectrometry, this does not necessarily mean that this species is indeed part of the catalytic cycle.

In this account we discuss a mass spectrometric method that enables unambiguous identification of intermediates involved in the enantioselective step of a catalytic cycle. This method, which we originally developed for screening chiral catalysts and catalyst mixtures, is based on monitoring the back reaction of mass-labeled quasienantiomeric products by electrospray ionization mass spectrometry (ESI-MS). ${ }^{[3,4]}$ In this way the intrinsic enantioselectivity of a chiral catalyst can be determined directly by quantification of catalytically relevant intermediates. In contrast to conventional screening methods based on product analysis, the results are not affected by catalytically active impurities or a non-catalytic background reaction. Moreover, mixtures of chiral catalysts with different molecular masses can be screened simultaneously, which is not possible by product analysis. Although application of this method is limited to reactions that show some degree of reversibility and proceed via catalytic intermediates that are detectable by ESIMS, we have shown that a variety of synthetically important reactions is amenable to back reaction screening. Examples are Pd-catalyzed allylic substitutions, ${ }^{[3 a, d]} \mathrm{Cu}$ - and organocatalyzed Diels-Alder reactions, ${ }^{[3 \mathrm{~b}]}$ and organocatalytic aldol, ${ }^{[5]}$ Michael, ${ }^{[3 \mathrm{c},}$ ${ }^{6]}$ and Morita-Baylis-Hillman reactions. ${ }^{[7]}$

The basic concept of our back reaction screening method is shown in Scheme 1. Starting from a 1:1 mixture of masslabeled quasi-enantiomeric reaction products $(R)-\mathbf{P}$ and $(S)-\mathbf{P}^{\prime},{ }^{[8]}$ a back reaction leading to components $\mathbf{A}^{\mathrm{L} 1}, \mathbf{A}^{\mathrm{L} 2}$ and $\mathbf{B}$ is induced by addition of a chiral catalyst. Shortly after, a sample is taken and analyzed by ESI-MS. From the signals of the mass-labeled fragment-catalyst adducts $\mathbf{A}^{\mathrm{L} 1}$-cat and $\mathbf{A}^{\mathrm{L} 2}$-cat their ratio can be determined, which is equivalent to the ratio of the rates of conversion of $(R)-\mathbf{P}$ and $(S)-\mathbf{P}^{\prime}$ to $\mathbf{A}^{\mathrm{L} 1}$ and $\mathbf{A}^{\mathrm{L} 2}$. Although the concentration of catalytic intermediates is generally very low, we have experienced that in most cases their signals can be reliably detected and the relative intensities quantified with sufficient accuracy, due to the high sensitivity of ESI-MS. Because the steps interconnecting the reactants $\mathbf{A}^{\mathrm{L} 1}$ and $\mathbf{A}^{\mathrm{L} 2}$ with products $(R)-\mathbf{P}$ and $(S)-\mathbf{P}^{\prime}$ are reversible, sampling has to be done in the initial phase of the reaction (typically after $\leq 1$ turnover), in order to avoid problems caused by racemization of $(R)$-P and $(S)-\mathbf{P}$.

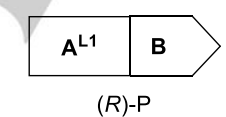

$(R)-\mathrm{P}$

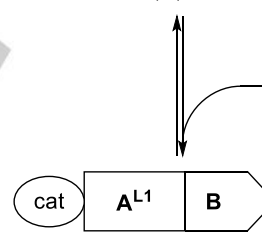

(R)-P-cat

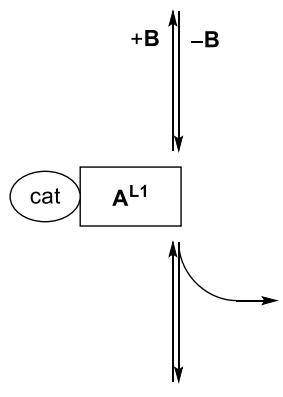

$A^{\mathrm{L1}}$

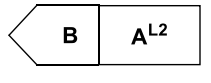

$(S)-P^{\prime}$

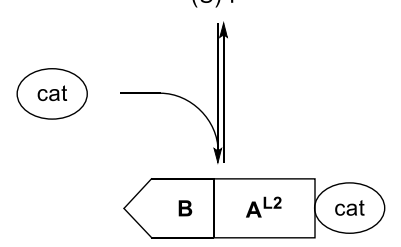

(S)-P'-cat

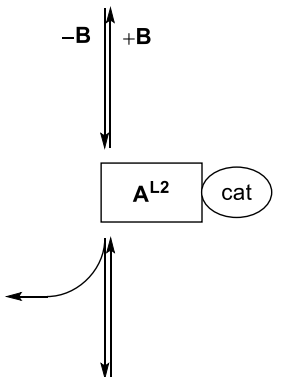

$A^{\mathrm{L2}}$
Scheme 1. Basic principle of back reaction screening.

If the step, in which the substrate-catalyst complex A-cat reacts with $\mathbf{B}$, is rate-determining in the forward reaction, the enantioselectivity of the overall reaction will be determined by the energy difference of the transition states of this step leading to $(R)$ - and (S)-P-cat. In this case, the same transition states 
also control the enantioselectivity of the back reaction, according to the principle of microscopic reversibility. Under this kinetic regime, formation of the catalyst-product adducts $(R)$-P-cat and $(S)-\mathbf{P}^{\prime}$-cat from $(R)-\mathbf{P}$ and $(S)-\mathbf{P}^{\prime}$ in the back reaction is fast and reversible, followed by a slow rate-determining bond cleavage leading to $\mathbf{A}^{\mathrm{L} 1}$-cat and $\mathbf{A}^{\mathrm{L} 2}$-cat (Curtin-Hammet conditions). Consequently, the ratio $A^{\mathrm{L} 1}$-cat/ $\mathbf{A}^{\mathrm{L} 2}$-cat determined by back reaction screening should be identical to the enantiomeric ratio $(R)-\mathbf{P} /(S)-\mathbf{P}$ observed for the preparative reaction in the forward direction.

A close match between the enantiomeric ratio produced in the forward reaction and the ratio $\mathbf{A}^{\mathrm{L} 1}$-cat/ $\mathbf{A}^{\mathrm{L} 2}$-cat measured for the back reaction would provide strong evidence that the substrate-catalyst complex A-cat is involved in the rate- and enantioselectivity-determining step. If the selectivities of the forward and back reaction differ, this would imply that a different step in the catalytic cycle is responsible for the observed enantioselectivity. In this way mechanistic insights into the enantioselective step of a catalytic process can be obtained, which are not directly available by other methods. In the following sections we demonstrate the potential of our ESI-MSbased methodology with different examples of catalytic reactions that we have analyzed by back reaction screening.

Patrick G. Isenegger was born in Basel, Switzerland, in 1988. He studied chemistry at the University of Basel, receiving his master degree in 2012. In 2012, he joined the research group of Andreas Pfaltz as a PhD student. His PhD topic is focused on the development of new catalysts for the Morita-Baylis-Hillman reaction and screening methods based on mass spectrometry.

Andreas Pfaltz obtained a PhD degree from ETH Zürich under the direction of Albert Eschenmoser in 1978. After postdoctoral research with Gilbert Stork at Columbia University he returned to ETH for his Habilitation. From 1990-1995 he was Professor of Organic Chemistry at the University of Basel and from 1995-1998 director at the Max Planck Institute for Coal Research in Mülheim an der Ruhr. In 1999 he returned to the University of Basel as Professor of Chemistry. Since August 2015 he holds the position of Emeritus Professor. His research interests focus on catalytic methods for organic synthesis, with special emphasis on asymmetric catalysis. His contributions have been recognized by a number of awards, including the Prelog Medal from ETH, the Noyori Prize, the Yamada-Koga Prize, and the Chirality Medal.

\section{2. $\alpha$-Functionalization of Carbonyl Compounds}

Organocatalytic enantioselective functionalization of carbonyl compounds at the $\alpha$-position by reaction with an electrophile is a central reaction type in organocatalysis. Many different chiral secondary amines have been used as catalysts for the reaction of aldehydes and ketones with various electrophiles. ${ }^{[9]}$ The most widely accepted mechanism for reactions of this type involves an enamine as the central intermediate which undergoes $\alpha$ functionalization with the electrophile (Scheme 2, left cycle). As an alternative, a catalytic cycle has been proposed that proceeds via an enol that interacts with the catalyst through hydrogen bonding (Scheme 2, right cycle). Although convincing evidence has accumulated over the years that supports an enamine mechanism, ${ }^{[10]}$ an enol mechanism cannot be strictly ruled out based on the available experimental data. In fact, several experimental and computational studies have been published that favor an enol mechanism for aldol and other $\alpha$ functionalization reactions, ${ }^{[11]}$ as originally postulated by Hajosh and Parrish for proline-catalyzed intramolecular aldol reactions. ${ }^{[12]}$

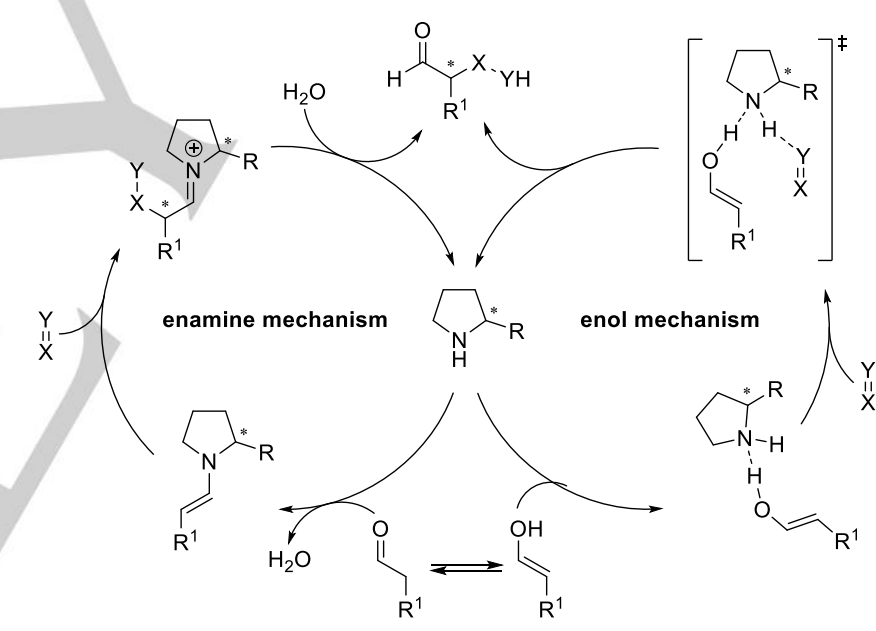

Scheme 2. Enamine versus enol mechanism

We thought that the back reaction screening approach explained above could help to resolve this controversy. In the following we show how this methodology made it possible to unambiguously establish the role of enamines as intermediates in two different $\alpha$-functionalization reactions.

\subsection{Aldol Reaction}

We have recently developed a back reaction screening protocol for the aldol reaction ${ }^{[5]}$ of acetone with para-nitrobenzaldehyde, using the quasienantiomeric aldol products $\mathbf{1 a}$ and $\mathbf{1} \mathbf{b}$ derived from acetone and fully $\left[{ }^{13} \mathrm{C}\right]$-labeled acetone as substrates. Although $\left[{ }^{13} \mathrm{C}\right]$-labeled acetone is expensive, the incurring costs are negligible because screening experiments can be done on a 
very small scale (10 $\mu \mathrm{M}$ or less) due to the high sensitivity of ESI-MS analysis. Addition of an amine catalyst to a solution containing a 1:1 mixture of quasienantiomers $\mathbf{1 a}$ and $\mathbf{1} \mathbf{b}$ initiated retro-aldol cleavage to acetone and para-nitrobenzaldehyde even at room temperature. When a sample was taken after 5-30 min, diluted, and injected into the mass spectrometer, the signals of the corresponding iminium ions $\mathbf{2 a}$ and $\mathbf{2} \mathbf{b}$ and the protonated catalyst-enamine intermediates $\mathbf{3 a}$ and $\mathbf{3} \mathbf{b}$ were clearly visible in the spectrum (Scheme 3 ).<smiles>CC(=O)C[C@H](O)c1ccc([N+](=O)[O-])cc1</smiles>
$1 \mathrm{a}$<smiles>[13CH3][13C](=O)[14CH2][C@@H](O)c1ccc([N+](=O)[O-])cc1</smiles><smiles>CCCC[Tl]</smiles><smiles>[X]C1CCCN1C(C)C[C@@H](O)c1ccc([N+](=O)[O-])cc1</smiles>
2a<smiles>[V]C1CCCCC1</smiles><smiles>[Y]C1CCCN1C(=C)C</smiles>

$3 a$<smiles>[TeH][TeH]</smiles>

1b

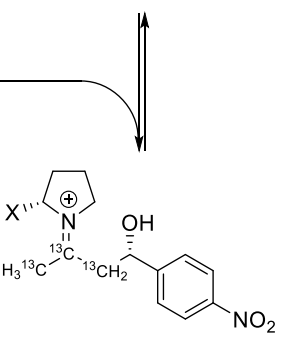

2b<smiles>O=Cc1ccc([N+](=O)[O-])cc1</smiles><smiles>CC1CC1[13CH]</smiles>

Scheme 3. Principle of the back reaction screening of the aldol reaction.

Under optimized conditions, using acetonitrile as solvent and acetic acid or 2,6-di-tert-butyl-4-nitrophenol (tert-BNP) as additive, a series of proline-derived organocatalysts was screened. The ratios of the protonated catalyst-enamine intermediates $\mathbf{3 a} \mathbf{a} \mathbf{3} \mathbf{b}$ were then compared with the enantiomeric ratios of the forward reaction determined by HPLC analysis of the products on a chiral stationary phase. The close match between the selectivities of the forward and back reaction, which was generally observed, provides strong evidence for an enamine mechanism. From these results it can be concluded that the reaction of the enamine intermediate with the aldehyde is the rate- and enantioselectivity-determining step in the forward reaction. Accordingly, formation of the catalyst adducts $2 a$ and $\mathbf{2 b}$ in the back reaction must be fast and reversible, while the subsequent retro-aldol cleavage leading to paranitrobenzaldehyde and enamines $\mathbf{3 a}$ and $\mathbf{3 b}$ is slow and ratedetermining. Based on these findings, a mechanism via enol intermediates, even as a minor competing pathway, can be ruled out. If such a pathway would run in parallel, it would mean that it must exhibit exactly the same enantioselectivity as the enamine

pathway, which is highly unlikely. By the same argument, other potential mechanisms that do not involve enamine intermediates, such as general chiral base catalysis, can be excluded.

Table 1. Comparison of the results from forward and back reaction screening. ${ }^{[a]}$

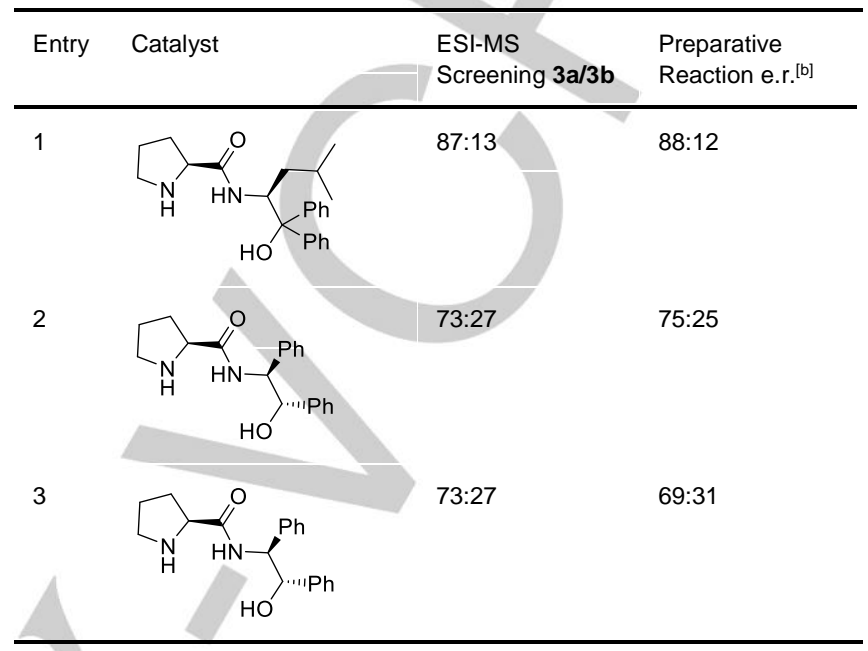

[a] Reaction conditions: para-nitrobenzaldehyde (1.0 eq), acetone (10 eq), $10 \mathrm{~mol} \%$ catalyst, $10 \mathrm{~mol} \%$ tert-BNP, $\mathrm{CH}_{3} \mathrm{CN}$, room temperature, $24 \mathrm{~h}$. [b] Determined by HPLC on a chiral stationary phase.

\subsection{Conjugate Addition of Aldehydes to Nitroolefins}

Organocatalytic enantioselective conjugate additions of aldehydes to nitroolefins are synthetically highly valuable transformations, as the resulting $\gamma$-nitroaldehydes can be converted to wide variety of products. ${ }^{[13]}$ Among the many chiral amine-based catalysts that have been used for this reaction, the tripeptide $\mathrm{H}-\mathrm{D}-$ Pro-Pro-Glu- $\mathrm{NH}_{2}{ }^{[14]}$ developed by Wennemers and coworkers stands out because of its unusually high reactivity combined with excellent enantioselectivity. Based on mechanistic studies a catalytic cycle via an enamine intermediate was proposed, in which the C-C bond forming step is rate- and enantioselectivity-determining. It was also found that the presence of a carboxylic acid function in the catalyst has a significant positive influence on the enantioselectivity and catalytic activity. ${ }^{[15]}$ Although less likely, an enol mechanism could not be strictly ruled out by the available mechanistic data. With the aim of resolving this mechanistic uncertainty, we started a collaborative study with the Wennemers group using our back reaction screening methodology as a mechanistic tool. ${ }^{[16]}$

After initial mass spectrometric studies had shown that the reaction is indeed reversible, a pair of quasi-enantiomeric nitroMichael products was synthesized in an enantioselective fashion using the two enantiomers of the Wennemers catalyst. The mass-labels ( $\mathrm{Me}$ and $\mathrm{Et}$ ) were installed at the para-position of the phenyl ring of the nitro-Michael adducts $\mathbf{4 a}$ and $\mathbf{4 b}$. Initial back reaction studies in DMSO showed that the charged imine intermediates $\mathbf{5 a}$ and $\mathbf{5 b}$ and the protonated enamine intermediates $6 \mathbf{a}$ and $\mathbf{6 b}$ could be readily detected by ESI-MS 
(Scheme 4). Although $\mathrm{CHCl}_{3} / \mathrm{PrOH}$ is the solvent of choice for preparative reactions, as it provides optimum stereoselectivity and reactivity, it proved to be unsuitable in this case, because the signals of the protonated enamines $\mathbf{6 a}$ and $\mathbf{6 b}$ were not visible, when this solvent was used. DMSO on the other hand turned out to be ideal for this study because enamines are known to be more stable in aprotic compared to protic media, resulting in higher signal intensities. Moreover, the lower enantioselectivities in DMSO $(46 \%$ ee vs. $97 \%$ ee in $\mathrm{CHCl}_{3} / \mathrm{PrOH}$ ) had the advantage that the signal of the minor enamine intermediate was sufficiently strong to enable reliable quantification.<smiles>O=CC(Cc1ccccc1)[C@H](C=O)c1ccc([N+](=O)[O-])cc1</smiles>

$4 a$

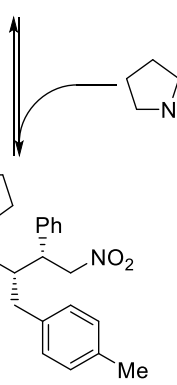
5 a

$6 a$<smiles>Cc1ccc(C[C@H](/C=N/[C@@H]2CCC[C@H]2c2ccccc2)C[N+](=O)[O-])cc1</smiles><smiles>CCc1ccc(CC(C(=O)O)c2ccccc2)cc1</smiles>

4b

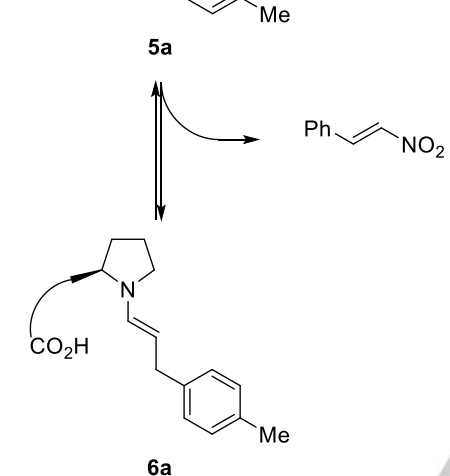

Scheme 4. Principle of the back reaction screening of the nitro-Michael addition.

The enamine ratios $6 \mathbf{a} / \mathbf{6 b}$ measured for the back reaction in DMSO exactly matched the corresponding enantiomeric ratios determined for the forward reaction (Table 2, entry 1). The enamine ratios obtained from related tripeptide catalysts as well were in perfect agreement with the enantioselectivity of the forward reaction (entries 2 and 3 ). The ratios of the imine intermediates $\mathbf{5 a} / \mathbf{5} \mathbf{b}$ ranged between $1: 1$ and $1: 2$ (with the minor species corresponding to the major enantiomer formed in the forward reaction). These ratios were not correlated to the e.r. values of the forward reaction, consistent with a Curtin-Hammett scenario for the back reaction, in which the imine intermediates $\mathbf{5 a}$ and $\mathbf{5 b}$ are in rapid equilibrium with nitroaldehydes $\mathbf{4 a}$ and $\mathbf{4 b}$
Table 2. Comparison of the results from forward and back reaction screening. ${ }^{[a]}$

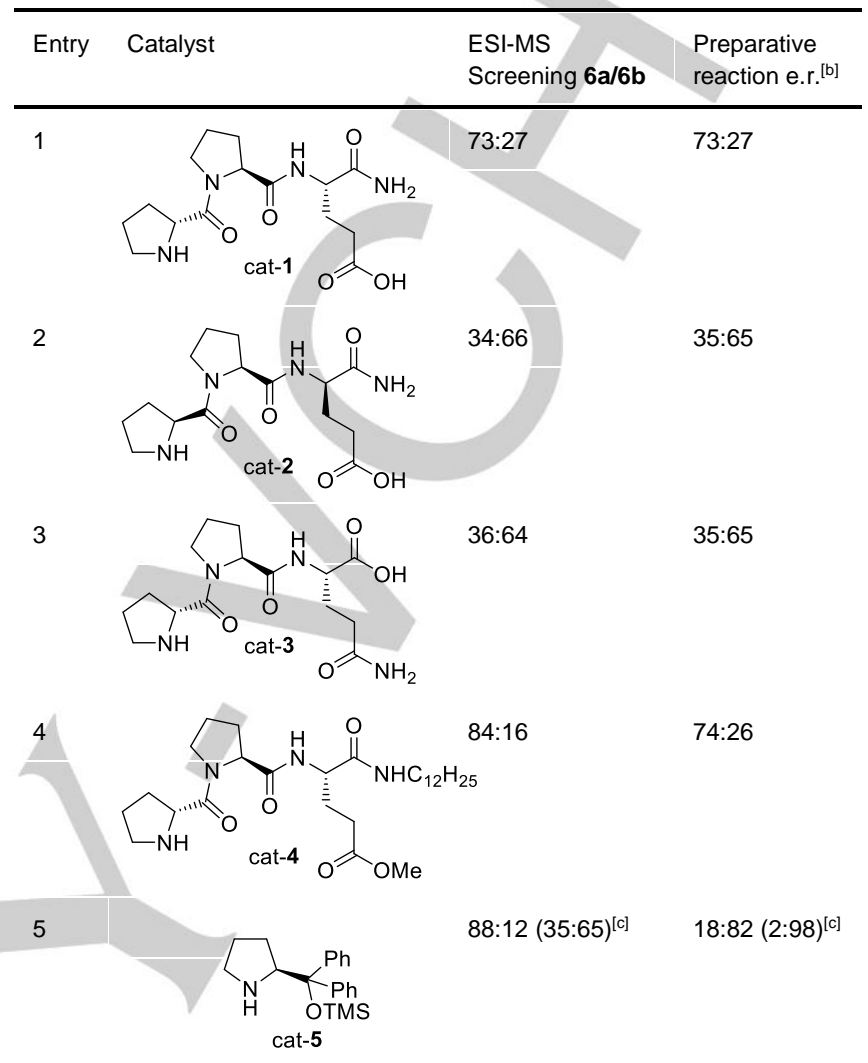

[a] Reaction conditions: 3-phenylpropanal (1.5 eq.), trans- $\beta$-nitrostyrene (1.0 eq.), 10 mol\% catalyst, DMSO, room temperature. [b] Determined by $\mathrm{HPLC}$ on a chiral stationary phase. [c] $\mathrm{CF}_{3} \mathrm{CH}_{2} \mathrm{OH}$ was used as solvent.

The close matches between the selectivities of the forward and back reaction measured for several catalysts strongly support the originally proposed catalytic cycle via an enamine intermediate, which adds to the nitroolelfin in the rate- and enantioselectivity-determining step (Figure 1a). At the same time an enol mechanism as shown in Scheme 2 can be ruled out Based on these results, a qualitative reaction profile can be drawn (Figure 1b), which implies that in the forward reaction the slow turnover-limiting $\mathrm{C}-\mathrm{C}$ bond forming step is followed by a fast proton transfer from the side chain of the catalyst, which has no influence on the enantioselectivity. 
a)
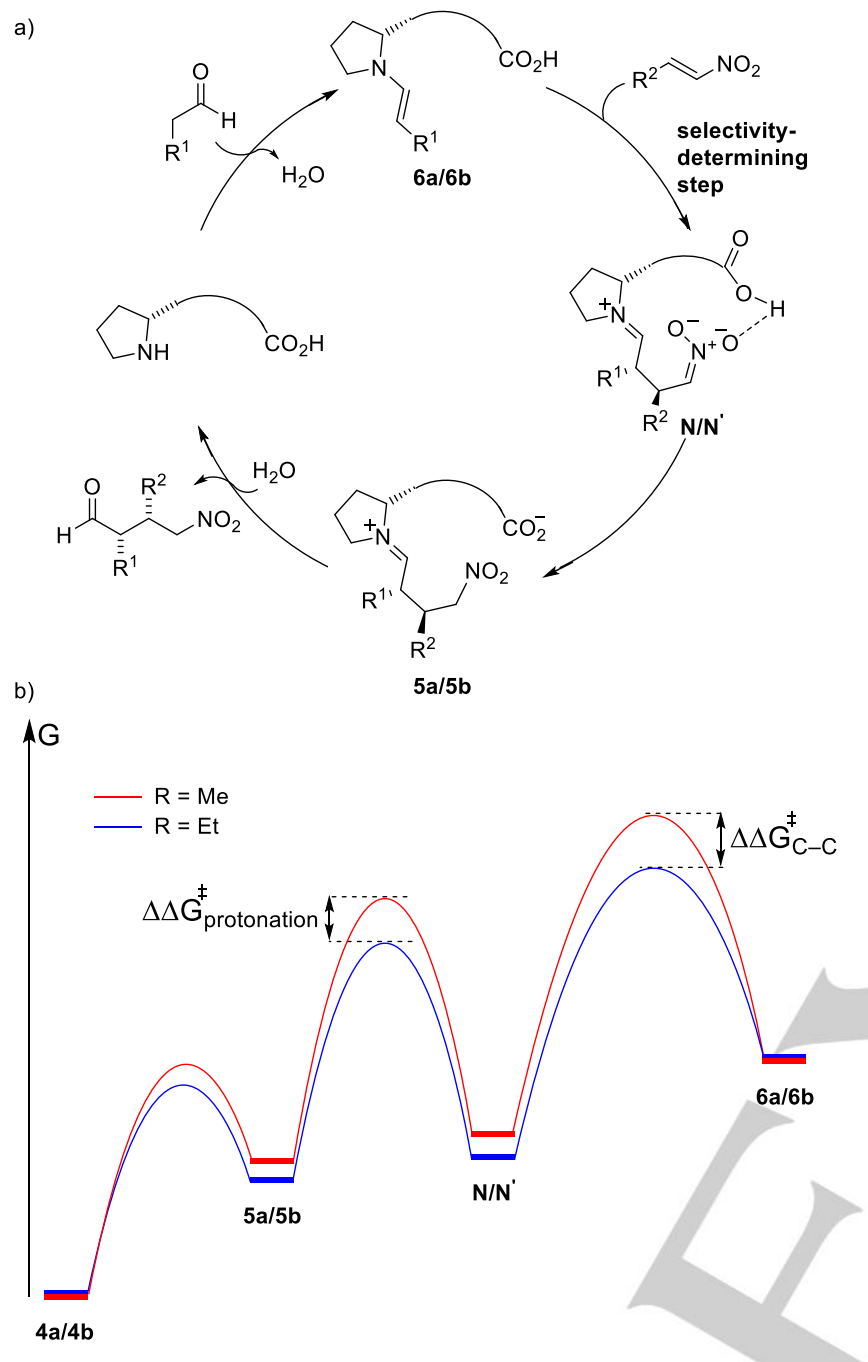

Figure 1. Proposed mechanism for catalysts with an intramolecular proton donor with a corresponding qualitative energy profile.

The crucial role of the carboxylic acid side chain in the tripeptide catalyst is reflected by the results obtained with analogous tripeptide catalysts such as cat-4 lacking an acidic group or the Hayashi-Jørgensen catalyst ${ }^{[13 h, 13 i]}$ cat-5. With these non-acidic catalysts the selectivities measured for the back reaction differed from the enantiomeric ratios resulting from the forward reaction (Table 2, entries 4 and 5). Most notably, the Hayashi-Jørgensen catalyst showed a drastic mismatch in the back reaction favoring the enamine intermediate corresponding to the minor product enantiomer of the forward reaction. This means, the enamine intermediate is not involved in the enantioselectivity-determining step of the forward reaction. Thus a different step in the catalytic cycle must be responsible for the observed enantioselectivity, in line with recent mechanistic studies by Pinko ${ }^{[17]}$ and Wennemers, ${ }^{[15 c]}$ which indicated that the protonation step became rate-determining with catalysts lacking an acidic group that is properly positioned for an intramolecular proton transfer.

Several groups who studied reactions of non-acidic pyrrolidine catalysts identified cyclobutanes and dihydrooxazines as intermediates and resting state. ${ }^{[18]}$ Moreover, it was found that acid additives accelerate reactions with non-acidic catalysts. Therefore, we decided to examine the effect of external acids on the back reaction with the Hayashi-Jørgensen catalyst cat-5.

With increasing amounts of para-nitrophenol as additive the enamine ratio decreased from $88: 12$ (no additive) to $67: 33$ (0.1 equiv.) and 57:43 (1 equiv.), while the e.r. in the forward reaction improved from 18:82 to $11: 89$ and 3:97. In 2,2,2,-trifluoroethanol as a moderately acidic solvent a reversal of the enamine ratio to $35: 65$ was observed (Table 1, entry 5), favoring now the mass-labeled enamine corresponding to the major product enantiomer in the forward reaction. However, the selectivity was still significantly lower than the e.r. of 2:98 measured for the preparative reaction in trifluoroethanol.

These results are consistent with the qualitative energy profile in Figure $2 \mathrm{~b}$. In the absence of an acid additive, the transition state of the protonation step is significantly higher in energy than the transition state of the C-C bond forming step. As expected, addition of an acid additive accelerates protonation. However, even at high acid concentration the transition state energy of the protonation step does not decrease to such an extent that it does not affect the rate and enantioselectivity anymore. Apparently, an external acid has a much weaker effect on the protonation rate than the properly positioned internal acid in the tripeptide catalyst cat-1. Although in reactions with the tripeptide catalyst, the overall acid concentration is very low, the intramolecular nature of the proton transfer renders this step much faster than $\mathrm{C}-\mathrm{C}$ bond formation.

The wealth of mechanistic information that has resulted from back reaction screening of conjugate additions to nitroolefins clearly demonstrates the potential of this methodology. The experiments described in this section allowed unambiguous confirmation of an enamine mechanism and exclusion of alternative pathways via enol intermediates. Moreover, the data provided revealing insights about the kinetic profile, the role of the carboxylic acid side chain in the Wennemers catalyst, and the effects of acid additives. 
a)

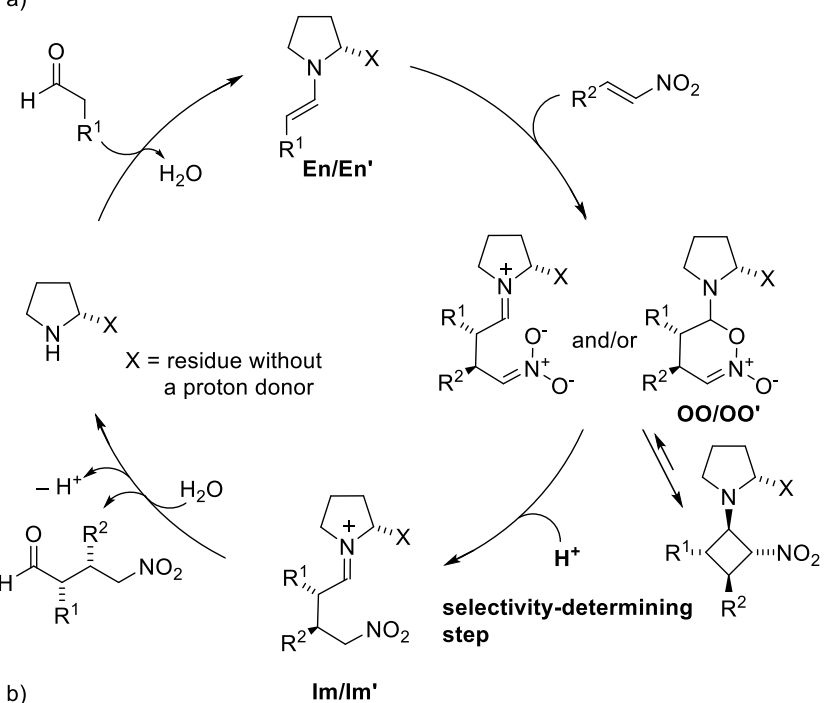

b)

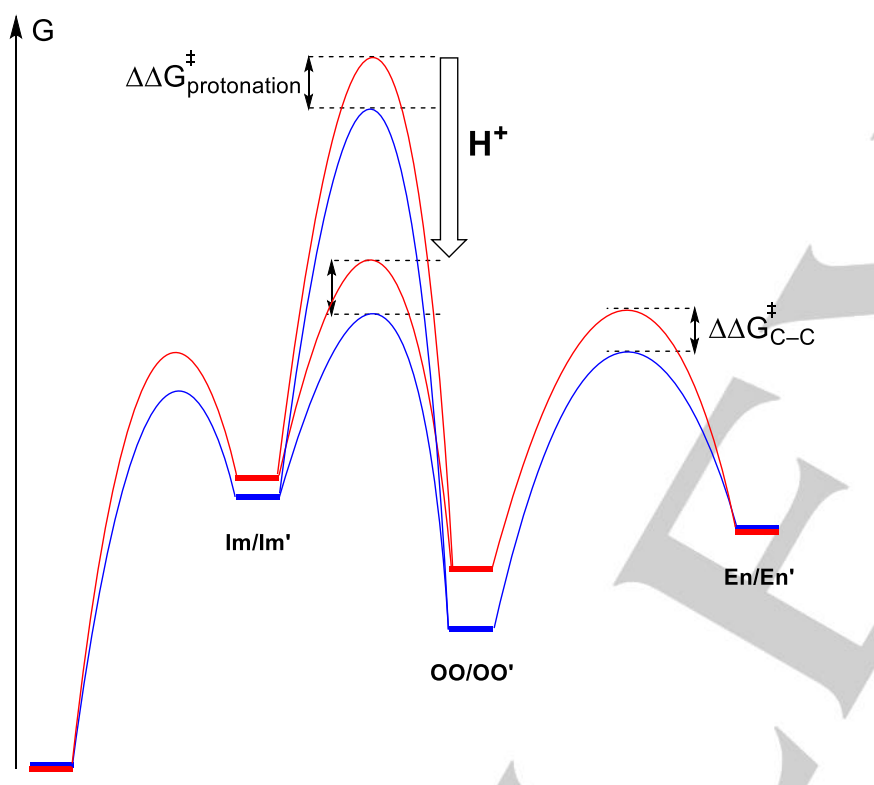

Figure 2. Proposed mechanism for catalysts lacking an intramolecular proton donor with a corresponding qualitative energy profile.

\section{Organocatalytic Diels-Alder Reaction}

Diels-Alder reactions are in principle reversible and therefore amenable to back reaction screening. ${ }^{[3 b]}$ Initially, we developed a screening protocol for chiral $\mathrm{Cu}(\mathrm{II})-\mathrm{BOX}$ complexes, which had been introduced by Evans and coworkers as catalysts. ${ }^{[19]}$ Subsequently, we extended our study to the organocatalytic Diels-Alder reaction developed by MacMillan and coworkers. ${ }^{[20]}$ As quasi-enantiomeric substrates, Diels-Alder products $7 \mathbf{a}$ and 7b were used that carried a mass label in the para-position of the phenyl ring. Upon treatment with catalytic amounts of imidazolidinone 8 , even at room temperature the catalystdienophile adducts $10 \mathrm{a}$ and $10 \mathrm{~b}$ could be detected by ESI-MS

(Scheme 5). The ratio of these intermediates (88:12) closely matched the e.r. of the Diels-Alder products determined for the forward reaction. These findings support the commonly accepted catalytic cycle via an iminium ion formed from the dienophile and the catalyst. According to the observed perfect agreement between the selectivities of the forward and back reaction, cycloaddition of the diene with the iminium intermediate is rate- and enantioselectivity-determining.

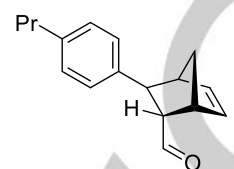

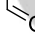

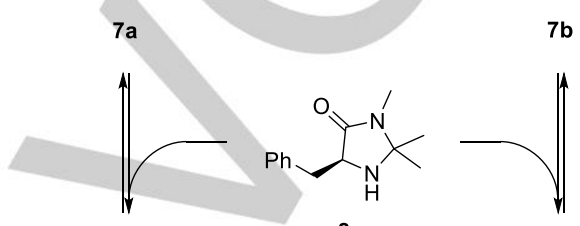

$\operatorname{Pr}$
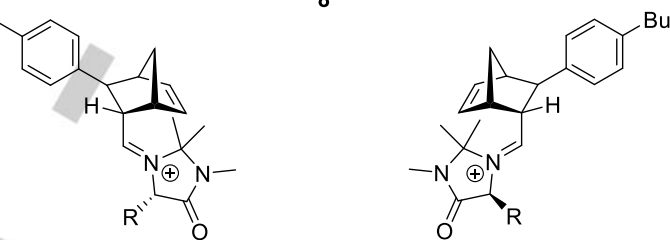

$9 a$
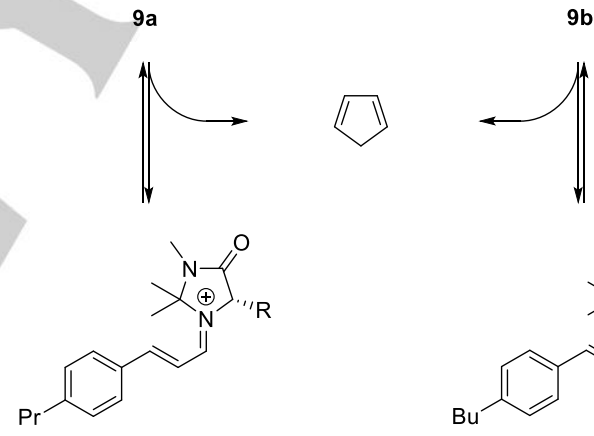

$10 \mathrm{a}$

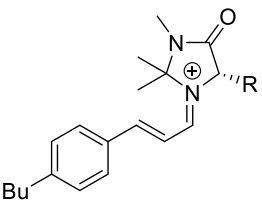

$10 \mathrm{~b}$

Scheme 5. Principle of the back reaction screening of an organocatalyzed DA reaction. 


\section{Organocatalytic Michael Additions to $\alpha, \beta-$ unsaturated Aldehydes}

$\alpha, \beta$-Unsaturated iminium species are also postulated as intermediates for the organocatalyzed Michael addition of malonates to $\alpha, \beta$-unsaturated aldehydes, ${ }^{[21]}$ which prompted us to study this reaction by back reaction screening (Scheme 6). ${ }^{\left[{ }^{[c]}\right]}$ When a 1:1 mixture of mass-labeled quasi-enantiomeric Michael adducts 11a and 11 b were treated with prolinol derivatives of the type originally used by Jørgensen as catalysts, ${ }^{[22]}$ iminium ions 13a/13b produced by retro-Michael reaction were clearly visible in the ESI mass spectrum after a reaction time of $2 \mathrm{~h}$ at room temperature (Table 3 ). In a series of experiments with different catalysts, the ratios $\mathbf{1 3 a} \mathbf{1} \mathbf{1 3 b}$ were in excellent agreement with the enantiomeric ratios of the forward reaction, confirming that the 1,4-addition of malonate to the iminium intermediate formed from the $\alpha, \beta$-unsaturated aldehyde represents the rate- and enantioselectivity-determining step<smiles></smiles>

11a<smiles>CCCCC</smiles><smiles>[X]C1CCCN1</smiles>

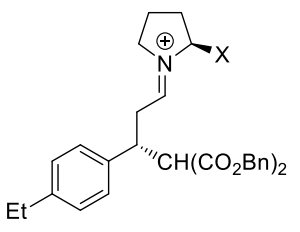
$12 \mathrm{a}$

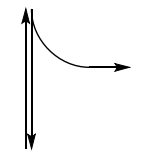<smiles>[X]C1CCCN1CC=Cc1ccc(CC)cc1</smiles>

$13 a$<smiles>CC(C)c1ccc(CCOC2CCCCC2)cc1</smiles>

11b
Table 3. Comparison of the results from forward and back reaction screening. ${ }^{[a]}$

\begin{tabular}{|c|c|c|c|}
\hline Entry & Catalyst & $\begin{array}{l}\text { ESI-MS } \\
\text { Screening } 13 a / 13 b\end{array}$ & 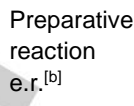 \\
\hline 1 & & $93: 7$ & $93: 7$ \\
\hline 2 & & $94: 6$ & $95: 5$ \\
\hline 3 & & $97: 3$ & $97: 3$. \\
\hline 4 & & $59: 41$ & $62: 38$ \\
\hline
\end{tabular}

[a] Reaction conditions: (E)-3-(4-ethylphenyl)acrylaldehyde (1.0 eq.), dibenzyl malonate $(1.0 \mathrm{eq}), 10 \mathrm{~mol} \%$ catalyst, $\mathrm{DCM} / \mathrm{EtOH}(9: 1)$, room temperature, two hours. [b] Determined by HPLC on a chiral stationary phase.

\section{Morita-Baylis-Hillman Reaction}

The Morita-Baylis-Hillman (MBH) reaction is a versatile synthetic method, which has found many applications in organic synthesis. ${ }^{[23]}$ Several enantioselective versions have been developed, but there is still a need for more selective and more broadly applicable catalysts. ${ }^{[24]}$ Although numerous mechanistic studies have been reported, many open questions about the catalytic cycle remain (see Scheme 7). Most studies focused on amines as catalysts. The results indicate that depending on the conditions, either the aldol step or the subsequent proton transfer may become rate- and enantioselectivity-determining. ${ }^{[25]}$ For phosphine-catalyzed $\mathrm{MBH}$ reactions only one mechanistic study was published, which reached the conclusion that the proton transfer was rate-determining, based on DFT calculations. ${ }^{[26]}$

We have recently developed a back reaction screening protocol for asymmetric $\mathrm{MBH}$ reactions with the aim to create a tool for rapid evaluation of chiral catalysts. In addition, we hoped to gain new mechanistic insights in this way.

Scheme 6. Principle of the back reaction screening of the Michael addition to $\alpha, \beta$-unsaturated aldehydes. 


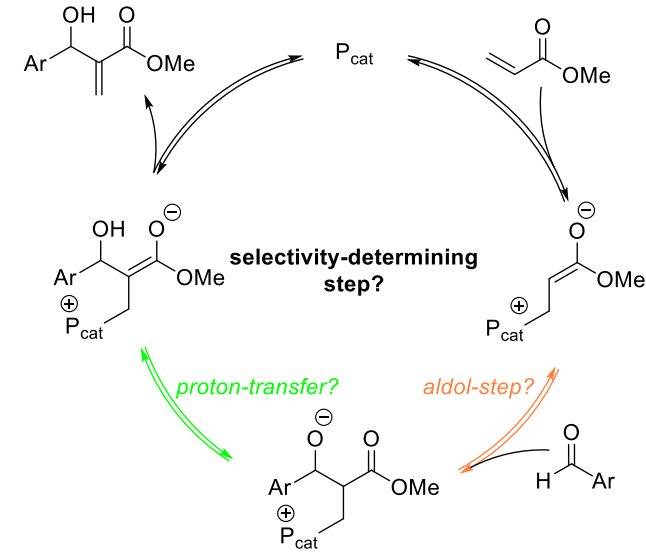

Scheme 7. Catalytic cycle of the $\mathrm{MBH}$ reaction.

Initial studies with triphenylphosphine as catalyst confirmed that the $\mathrm{MBH}$ reaction of methyl acrylate with paranitrobenzaldehyde is reversible and the catalyst-acrylate adduct formed in the retro-aldol step can be detected by ESI-MS. Subsequently, the quasi-enantiomeric $\mathrm{MBH}$ products $14 \mathrm{a}$ and 14b that carried a mass label in the ester group were synthesized and used as substrates in back reaction screening with a series of chiral bifunctional catalysts such as the phosphine-thiourea catalyst 20 developed by Wu. ${ }^{[27]}$ After a reaction time of $30 \mathrm{~min}$ in dichloromethane at room temperature, ESI-MS analysis clearly showed the signals of the cationic protonated species $17 a / 17 b$ and $19 a / 19 b$ derived from the zwitterionic product-catalyst adducts $15 a / 15 b$ and $16 a / 16 b$ and the catalyst-acrylate adducts $\mathbf{1 8} \mathbf{a} / \mathbf{1 8} \mathbf{b}$, respectively (see Figures 3 and 4 ). With catalyst $\mathbf{2 0}$, ratios of $69: 31$ for $\mathbf{1 7 a} / \mathbf{1 7 b}$ and $74: 26$ for $19 a / 19 b$ were measured. The ratio of product enantiomers in the forward reaction, determined by HPLC analysis on a chiral stationary phase, was $74: 26$, in perfect agreement with the ratio of the protonated mass-labeled catalyst-acrylate adducts $19 a / 19 b$, which is equivalent to the ratio of the catalytic intermediates $\mathbf{1 8} \mathbf{a} / \mathbf{1 8} \mathbf{b}$ formed in the retro-aldol step. With other catalysts as well, the ratios $19 a / 19 b$ produced in the back reaction closely matched the enantiomeric ratios of the forward reaction.

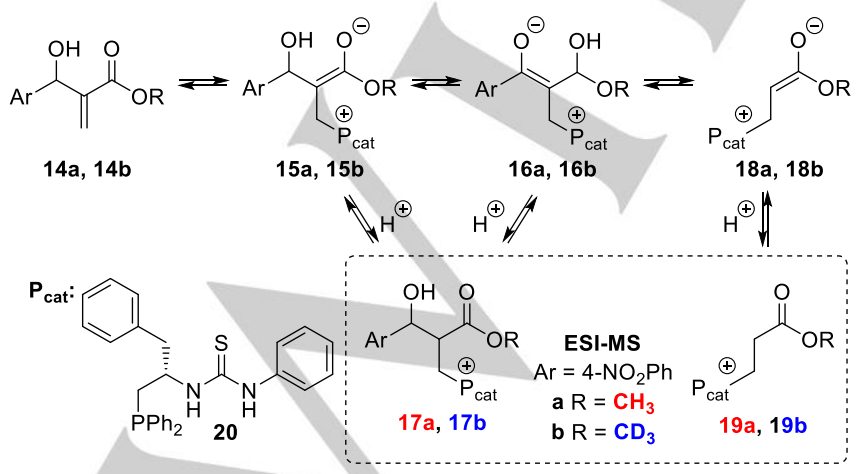

Figure 3. retro-MBH reaction and detected intermediates.

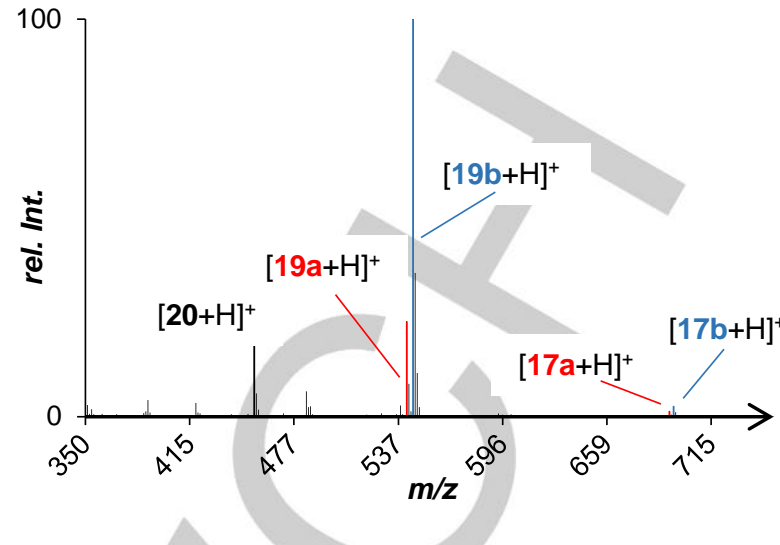

Figure 4. ESI-MS spectrum of the back reaction with catalyst 20.

These findings provide clear evidence that the aldol rather than the proton-transfer step is rate- and enantioselectivitydetermining. Beyond mechanistic investigations, our back reaction screening protocol provides an efficient tool for rapid evaluation of enantioselective $\mathrm{MBH}$ catalysts. ${ }^{[7]}$

\section{Conclusion}

The examples presented in this account demonstrate that mass spectrometric back reaction screening of quasi-enantiomeric products may serve as a valuable tool for examining the mechanism of an enantioselective catalytic process. By comparing the results from the forward and back reaction, direct evidence for the involvement of a catalytic intermediate in the enantioselective step can be obtained. Moreover, insights about the energy profile of the catalytic cycle may be gained. The specific mechanistic information that is accessible in this way is unique and complementary to the information available from other methods.

\section{Acknowledgements}

Financial support by the Swiss National Science Foundation is gratefully acknowledged.

Keywords: asymmetric catalysis • mass spectrometry • organocatalysis $\cdot$ reactive intermediates

[1] a) Comprehensive Asymmetric Catalysis (Eds.: E. N. Jacobsen, A. Pfaltz, H. Yamamoto), Springer, Berlin, 1999; b) Comprehensive Chirality (Eds.: E. M. Carreira, H. Yamamoto), Vol. 3-6, Elsevier, Amsterdam, 2012; c) Catalytic Asymmetric Synthesis (Ed. I. Ojima), 3rd ed., John Wiley, New York, 2010.

[2] a) A. S. C. Chan, J. J. Pluth, J. Halpern, J. Am. Chem. Soc. 1980, 102 5952-5964; b) C. R. Landis, S. Feldgus, Angew. Chem. Int. Ed. 2000, 39, 2863-2866; c) S. Feldgus, C. R. Landis, J. Am. Chem. Soc. 2000, 122, 12714-12727. d) R. Giernoth, H. Heinrich, N. J. Adams, R. J. 
Deeth, J. Bargon, J. M. Brown, J. Am. Chem. Soc. 2000, 122, 12381 12382.

[3] a) C. A. Müller, A. Pfaltz, Angew. Chem. Int. Ed. 2008, 47, 3363-3366; b) A. Teichert, A. Pfaltz, Angew. Chem. Int. Ed. 2008, 47, 3360-3362; c) I. Fleischer, A. Pfaltz, Chem. Eur. J. 2010, 16, 95-99; d) C. Ebner, C. A. Müller, C. Markert, A. Pfaltz, J. Am. Chem. Soc. 2011, 133, 4710-4713; e) Review: C. A. Müller, C. Markert, A. M. Teichert, A. Pfaltz, Chem. Commun. 2009, 1607-1618.

[4] See also: a) C. Markert, A. Pfaltz, Angew. Chem. Int. Ed. 2004, 43 2498-2500; b) C. Markert, P. Rösel, A. Pfaltz, J. Am. Chem. Soc. 2008 130, 3234-3235.

[5] F. Bächle, Ph.D. thesis, University of Basel 2014 (http://edoc.unibas.ch/diss/DissB_10837).

[6] F. Bächle, I. Fleischer, A. Pfaltz, Adv. Synth. Catal. 2015, 357, 22472254.

[7] P. G. Isenegger, F. Bächle, A. Pfaltz, manuscript in preparation

[8] Quasi-enantiomers $(R)-\mathbf{P}$ and $(S)-\mathbf{P}^{\prime}$ have the same reactivity as the parent enantiomers but differ in mass due to mass labels $\mathbf{L} 1$ and $\mathbf{L} 2$ at remote positions where they do not alter the reactivity; see: Q. Zhang, D. P. Curran, Chem. Eur. J. 2005, 11, 4866-4880.

[9] S. Mukherjee, J. W. Yang, S. Hoffmann, B. List, Chem. Rev. 2007, 107, 5471-5569.

[10] a) M. Klussmann in Science of Synthesis: Asymmetric Organocatalysis, Vol. 2 (Eds.; B. List, K. Maruoka), Thieme, Stuttgart, 2012, pp. 633-671; b) B. List, L. Hoang, H. J. Martin, Proc. Natl. Acad. Sci. USA 2004, 101 5839-5842; c) C. A. Marquez, F. Fabbretti, J. O. Metzger, Angew. Chem. Int. Ed. 2007, 46, 6915-6917; d) M. B. Schmid, K. Zeitler, R. M. Gschwind Angew. Chem. Int. Ed. 2010, 49, 4997-5003.

[11] a) C. T. Wong, Tetrahedron Lett. 2009, 50, 811-813; b) D. A. Yalalov, S. B. Tsogoeva, T. E. Shubina, I. M. Martynova, T. Clark Angew. Chem. Int. Ed. 2008, 47, 6624-6628; c) S. Belot, A. Quintard, N. Krause, A. Alexakis, Adv. Synth. Catal. 2010, 352, 667-695.

[12] Z. G. Hajos, D. R. Parrish, J. Org. Chem. 1974, 39, 1615-1621.

[13] J. M. Betancort, C. F. Barbas III, Org. Lett. 2001, 3, 3737-3740; b) A. Alexakis, O. Andrey, Org. Lett. 2002, 4, 3611-3614; c) D. Enders, A Seki, Synlett 2002, 26-28; d) H. J. Martin, B. List, Synlett 2003, 19011902; e) N. Mase, R. Thayumanavan, F. Tanaka, C. F. Barbas III, Org Lett. 2004, 6, 2527-2530; f) O. Andrey, A. Alexakis, A. Tomassini, G. Bernardinelli, Adv. Synth. Catal. 2004, 346, 1147-1168; g) M. P. Lalonde, Y. Chen, E. N. Jacobsen, Angew. Chem. Int. Ed. 2006, 45 6366-6370; h) J. Franzén, M. Marigo, D. Fielenbach, T. C. Wabnitz, A. Kjrsgaard, K. A. Jørgensen, J. Am. Chem. Soc. 2005, 127, 1829618304; i) Y. Hayashi, H. Gotoh, T. Hayashi, M. Shoji, Angew. Chem. Int. Ed. 2005, 44, 4212-4215.

[14] a) M. Wiesner, J. D. Revell, H. Wennemers, Angew. Chem. Int. Ed. 2008, 47, 1871-1874; b) M. Wiesner, J. D. Revell, S. Tonazzi, H. Wennemers, J. Am. Chem. Soc. 2008, 130, 5610-5611; c) M. Wiesner, H. Wennemers, Synthesis 2010, 1568-1571; d) Y. Arakawa, M. Wiesner, H. Wennemers, Adv. Synth. Catal. 2011, 353, 1201-1206; e) Y. Arakawa, H. Wennemers, ChemSusChem 2013, 6, 242-245.

[15] a) M. Wiesner, M. Neuburger, H. Wennemers, Chem. Eur. J. 2009, 15 , 10103-10109; b) M. Wiesner, G. Upert, G. Angelici, H. Wennemers, J. Am. Chem. Soc. 2010, 132, 6-7; c) J. Duschmalé, J. Wiest, M. Wiesner, H. Wennemers, Chem. Sci. 2013, 4, 1312-1318.

[16] F. Bächle, J. Duschmalé, C. Ebner, A. Pfaltz, H. Wennemers, Angew. Chem. Int. Ed. 2013, 52, 12619-12623.

[17] G. Sahoo, H. Rahaman, Á. Madarász, I. Pápai, M. Melarto, A. Valkonen, P. M. Pihko, Angew. Chem. Int. Ed. 2012, 51, 13144-13148.

[18] a) K. Patora-Komisarska, M. Benohoud, H. Ishikawa, D. Seebach, Y. Hayashi, Helv. Chim. Acta 2011, 94, 719-745; b) J.Burés, A. Armstrong, D. G. Blackmond, J. Am. Chem. Soc. 2011, 133, 8822-8825; c) D. Seebach, X. Sun, C. Sparr, M.-O. Ebert, W. B. Schweizer, A. K. Beck, Helv. Chim. Acta 2012, 95, 1064-1078; d) D. Seebach, X. Sun, M.-O. Ebert, W. B. Schweizer, N. Purkayastha, A. K. Beck, J. Duschmal, H. Wennemers, T. Mukaiyama, M. Benohoud, Y. Hayashi, M. Reiher, Helv.
Chim. Acta, 2013, 96, 799-852; e) J. Bures, A. Armstrong, D. G. Blackmond, J. Am. Chem. Soc. 2012, 134, 6741-6750.

[19] D. A. Evans, S. J. Miller, T. Lectka, P. von Matt, J. Am. Chem. Soc 1999, 121, 7559-7573.

[20] K. A. Ahrendt, C. J. Borths, D. W. C. MacMillan, J. Am. Chem. Soc 2000, 122, 4243-4244

[21] a) S. Lakhdar, T. Tokuyasu, H. Mayr, Angew. Chem. Int. Ed. 2008, 47, 8723-8726; b) D. Seebach, U. Grošelj, D. M. Badine, W. B. Schweizer A. K. Beck, Helv. Chim. Acta 2008, 91, 1-13; c) U. Grošelj, D. Seebach, D. M. Badine, W. B. Schweizer, A. K. Beck, I. Krossing, P. Klose, Y Hayashi, T. Uchimaru, Helv. Chim. Acta 2009, 92, 1225-1259.

[22] S. Brandau, A. Landa, J. Franzén, M. Marigo, K. A. Jørgensen, Angew. Chem. Int. Ed. 2006, 118, 4411-4415.

[23] Y. Wei, M. Shi, Chem. Rev. 2013, 113, 6659-6690.

[24] a) J.-J. Gong, K. Yuan, X.-Y. Wu, Tetrahedron: Asym. 2009, 18, $2117-$ 2120. b) Y. Wei, M. Shi, Acc. Chem. Res. 2010, 43, 1005-1018. c) X Han, Y. Wang, F. Zhong, Y. Lu, Org. Biomol. Chem. 2011, 19, 6734 6740.

[25] a) R. Robiette, V. K. Aggarwal, J. N. Harvey, J. Am. Chem. Soc. 2007, 129, 15513-15525. b) D. Cantillo, C. O. Kappe, J. Org. Chem. 2010, 75 8615-8626; c) R. E. Plata, D. A. Singleton, J. Am. Chem. Soc. 2015 137, 3811-3826

[26] J. Xu, J. Mol. Struct. THEOCHEM 2006, 767, 61-66.

[27] J.-J. Gong, K. Yuan, H.-L. Song, X.-Y. Wu, Tetrahedron 2010, 66, 2439-2443. 
Entry for the Table of Contents (Please choose one layout)

Layout 1:

\section{PERSONAL ACCOUNT}

Text for Table of Contents

Layout 2:

\section{PERSONAL ACCOUNT}

((Insert TOC Graphic here))

Author(s), Corresponding Author(s)*

Page No. - Page No.

Title

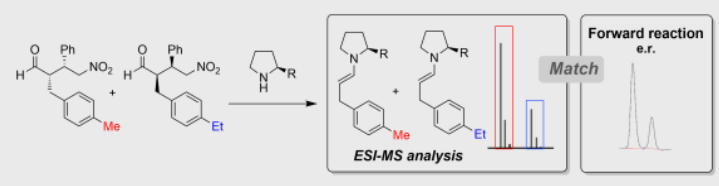

Mass spectrometric back reaction screening of quasi-enantiomeric products may serve as a valuable tool for examining the mechanism of an enantioselective catalytic process. By comparing the results from the forward and back reaction, direct evidence for the involvement of a catalytic intermediate in the enantioselective step can be obtained. The potential of this method is demonstrated for various organocatalytic asymmetric reactions.
P. G. Isenegger, A. Pfaltz*

Page No. - Page No.

Mass Spectrometric Back Reaction

Screening of Quasi-Enantiomeric Products as a Mechanistic Tool 